\title{
Bioavailability of nanoemulsified conjugated linoleic acid for an antiobesity effect
}

This article was published in the following Dove Press journal:

International Journal of Nanomedicine

I February 2013

Number of times this article has been viewed

\section{Dongyeop Kim $1,3 *$ \\ Jin-Hong Park ${ }^{2 *}$ \\ Dae-Jun Kweon ${ }^{2}$ \\ Gi Dong Han'}

'Department of Food Science and Technology, College of Natural Resources, Yeungnam University, Gyeongsan, Republic of Korea; ${ }^{2}$ BioHealth Convergence Center, Daegu Technopark, Daegu, Republic of Korea; ${ }^{3}$ Division of Applied Bioscience, Graduate School of Agriculture, Hokkaido University, Sapporo, Japan

*These authors contributed equally to this work
Correspondence: Gi Dong Han

Department of Food Science and

Technology, Yeungnam University,

Gyeongsan 712-749, Republic of Korea

Tel +8253810 2957

Fax +82 538104662

Email gdhan I@ynu.ac.kr
Background: The aim of this study was to enhance the bioavailability of conjugated linoleic acid (CLA), which has low water solubility, using nanoemulsion technology and to evaluate the effects of its improved bioavailability as an antiobesity agent.

Methods: The antiobesity effect of nanoemulsified water-soluble conjugated linoleic acid (N-CLA) was evaluated using in vitro and in vivo studies. Differentiated 3T3-L1 adipocytes were treated with CLA and N-CLA to assess their lipolytic effect. Further, to confirm the antiobesity effect of N-CLA, male Sprague-Dawley rats were randomly separated into four groups, ie, a group fed a normal diet, a group fed a high-fat diet (obesity rat model), a CLA-treated group, and an N-CLA-treated group.

Results: N-CLA showed a greater lipolytic effect on differentiated 3T3-L1 adipocytes compared with normal CLA. N-CLA enhanced the release of glycerol from triglycerides, which accumulated in differentiated 3T3-L1 adipocytes. Further, N-CLA enhanced leptin secretion to an extent similar to that of orlistat, an antiobesity agent. In an animal obesity model fed a high-fat diet, N-CLA attenuated accumulation of triglycerides, total cholesterol, and low-density lipoprotein cholesterol in serum, and also significantly decreased the volume of triglycerides and cholesterol in liver tissue.

Conclusion: These results indicate that N-CLA has a greater antiobesity effect than CLA as a result of its improved bioavailability.

Keywords: conjugated linoleic acid, nanoemulsion, water-soluble, improved bioavailability, antiobesity

\section{Introduction}

Many pharmacological agents, including amphetamine, orlistat, rimonabant, and sibutramine, are used in the management of obesity. However, numerous drugs have been withdrawn recently, due to their adverse effects and risk of myocardial infarction, psychiatric disorders, and stroke. ${ }^{1}$ Due to their adverse effects on the human body, novel agents with improved antiobesity properties and minimal side effects are in high demand. Among the alternative antiobesity medicines, conjugated linoleic acid (CLA) is considered to be effective. CLA is a fatty acid mixture of positional and geometric isomers of octadecadienoic acid (linoleic acid 18:2n-6) with a conjugated double-bond system. ${ }^{2}$ To date, CLA has attracted interest as a weight-reducing agent because of its antiobesity activity, ie, reduced lipid accumulation in adipocytes via inhibition of lipoprotein lipase activity and decreased body fat mass via induction of apoptosis in adipocytes. ${ }^{3-6}$ Furthermore, CLA increases muscle mass in mice and facilitates use of fat as an energy source. ${ }^{7}$ Although CLA is considered to be an alternative medicine 
with minimal side effects compared with the mainstream antiobesity drugs, it has been reported to induce upset stomach, nausea, and loose stools because of its lack of absorption and instability. ${ }^{8}$

Nanoemulsions, a class of emulsions with a droplet size of 20-500 nm, exist in both water-in-oil and oil-in-water forms, ${ }^{9}$ are composed of surfactants or emulsifiers, and are commonly used in food substances. Moreover, nanotechnology has been used in the development of nanoemulsions as pharmaceuticals over the last few years. ${ }^{10}$ Nanoemulsions are well characterized and have potential as a drug delivery system with practical pharmaceutical applications for the reduction of side effects. ${ }^{11}$

The aim of this study was to evaluate the antiobesity effect of nanoemulsified water-soluble conjugated linoleic acid (N-CLA) with improved bioavailability in water in a series of in vitro and in vivo studies.

\section{Materials and methods Materials}

CLA of greater than 77\% purity (Clarinol A80) was obtained from Lipid Nutrition (Wormerveer, The Netherlands). Dulbecco's modified Eagle's medium, fetal bovine serum, penicillin, and streptomycin were obtained from Gibco (Grand Island, NY, USA). 3-Isobutyl-1-methylxanthine, dexamethasone, pioglitazone, orlistat, and free glycerol reagent were purchased from Sigma-Aldrich (St Louis, MO, USA). Insulin (Arg-insulin) was obtained from Upstate (Lake Placid, NY, USA). All other chemicals used were of extra pure grade $(>99.0 \%$ purity).

\section{Preparation of N-CLA and determination of micelle size}

CLA and lecithin were dissolved in sugar ester and ethanol, and the product was then mixed with water and glycerin. To obtain N-CLA (containing 30\% CLA), the mixture was passed five times through a high-pressure homogenizer (M110F, Microfluidics Inc, Newton, MA, USA) at 1000 bar and then filter-sterilized. The sizes of the CLA and N-CLA micelles were measured using a zeta potential and particle size analyzer (ELS-Z, Photal, Otsuka Electronics, Osaka, Japan), and images of the micelles were obtained by transmission electron microscopy (JEM-1010, JEOL, Tokyo, Japan).

\section{Cell culture and sample treatment}

3T3-L1 preadipocytes (ATCC CL-173, American Tissue Culture Collection, Manassas, VA, USA) were grown in
Dulbecco's modified Eagle's medium containing 10\% fetal bovine serum and $1 \% \mathrm{P} / \mathrm{S}$ at $37^{\circ} \mathrm{C}$ in a $5 \% \mathrm{CO}_{2}$ incubator. Confluent cells were differentiated for 2 days in MDI medium containing $1 \%$ penicillin-streptomycin, $5 \%$ fetal bovine serum, $10 \mu \mathrm{g} / \mathrm{mL}$ of insulin, $0.5 \mathrm{mM} 3$-isobutyl-1-methylxanthine, $1 \mu \mathrm{M}$ dexamethasone, and $10 \mu \mathrm{M}$ pioglitazone. The post-differentiation medium (MDI medium, excluding 3-isobutyl-1-methylxanthine and dexamethasone) was replaced every 2 days. After differentiation was complete, the cells were matured in high-glucose Dulbecco's modified Eagle's medium containing $10 \mu \mathrm{g} / \mathrm{mL}$ of insulin. The samples were then dissolved in dimethyl sulfoxide and treated at a final concentration of $10 \mu \mathrm{g} / \mathrm{mL}$ (molar concentration $3.57 \mu \mathrm{M}$ ). This CLA concentration is appropriate for stimulation of de novo lipogenesis with no cytotoxic effects. ${ }^{12}$ The control was treated with vehicle (dimethyl sulfoxide) only.

\section{Cell viability assay}

Cell viability was measured as previously described using the 3-(4,5-dimethylthiazol-2-yl)-2.5-diphenyltetrazolium (MTT) assay. ${ }^{13}$ Preadipocytes $\left(1 \times 10^{4}\right)$ were placed into each well of a 96 -well plate, after which they were incubated at $37^{\circ} \mathrm{C}$ in a $5 \% \mathrm{CO}_{2}$ incubator for 24 hours. MTT (final concentration $0.4 \mu \mathrm{g} / \mathrm{mL}$ in phosphate-buffered saline) was added after 24 hours. After 4 hours, the newly formed formazan crystals were dissolved in dimethyl sulfoxide and ethanol at a ratio of $1: 1$, after which absorbance was measured at $540 \mathrm{~nm}$ using a microplate reader (Sunrise, Tecan, Vienna, Austria). Cell viability was determined based on the ratio of the absorbance of the sample-treated group to that of the control group.

\section{Oil Red $O$ staining and triglyceride quantification}

Cells were stained with Oil Red $\mathrm{O}$ after adipocyte differentiation, then washed twice with phosphate-buffered saline and fixed with $10 \%$ formaldehyde in phosphate-buffered saline for one hour. After the formaldehyde was discarded, Oil Red $\mathrm{O}$ was added to isopropanol for one hour. Stained droplets were dissolved in the isopropanol and then quantified by measuring absorbance at $490 \mathrm{~nm}$. The results are shown as relative triglyceride content compared with the control.

\section{Glycerol content analysis}

Glycerol was quantified according to the enzyme reaction method using free glycerol reagent. Briefly, $10 \mathrm{~mL}$ of medium, collected after cells were treated with the sample for 24 hours, was added to $0.8 \mathrm{~mL}$ of free glycerol reagent prewarmed to $37^{\circ} \mathrm{C}$. The reaction was carried out in a 
waterbath at $37^{\circ} \mathrm{C}$ for 5 minutes. To quantify the amount of glycerol, standard glycerol $(25 \mu \mathrm{g} / 10 \mathrm{~mL})$ was reacted in the same manner as described above, after which absorbance was measured at $540 \mathrm{~nm}$. Glycerol content was calculated according to the following formula.

$$
\begin{aligned}
\text { Glycerol content }= & \frac{(A \text { sample }-A \text { blank })}{(A \text { standard }-A \text { blank })} \\
& \times \text { Concentration of standard }
\end{aligned}
$$

\section{Measurement of leptin content in 3T3-LI cell culture medium}

The amount of leptin secreted from the 3T3-L1 adipocytes was measured using a sandwich enzyme-linked immunosorbent assay following the method described by Mimura et al, ${ }^{14}$ with slight modification. Aliquots $(100 \mu \mathrm{L})$ of rabbit antimouse leptin IgG (Santa Cruz Biotechnology Inc, Santa Cruz, CA, USA) dissolved in phosphate-buffered saline were added to each well of a 96-well enzyme-linked immunosorbent assay plate, which was then incubated overnight at $4^{\circ} \mathrm{C}$ and washed three times with TPBS (phosphate-buffered saline +0.05 Tween 20$)$. Following this, aliquots $(100 \mu \mathrm{L})$ of the collected medium were added to the plate, which was then incubated at room temperature for one hour and subsequently washed three times with TPBS. Next, alkaline phosphatase-conjugated goat antirabbit IgG (Chemicon International Inc, Temecula, CA, USA) was added, followed by incubation at room temperature for one hour and washing three times with TPBS. The reaction was developed using an alkaline phosphatase conjugate substrate kit (5-bromo-4-chloro-3-indolyl phosphate $p$-toluidine salt/nitro blue tetrazolium, Bio-Rad, Hercules, CA, USA), after which absorbance was measured using an enzyme-linked immunosorbent assay reader at $490 \mathrm{~nm}$.

\section{Animals and diet}

Male Sprague-Dawley rats (5 weeks, $145 \pm 5 \mathrm{~g}$ ) were purchased from Orient Bio (Gyeonggi, Korea) and maintained at $25^{\circ} \mathrm{C} \pm 2{ }^{\circ} \mathrm{C}$ in cages with a relative humidity of $60 \% \pm 5 \%$ on a 12-hour light/dark cycle. Rats were fed laboratory chow (AIN-76 diet) for one week in order to stabilize their metabolic condition. The rats were divided into four groups (five rats per group) and allowed free access to food and water during the entire experimental period. The AIN-76 diet was used as the base for the experimental diet. Test materials were added at a level of $2 \%$ (30\% CLA constituted in test materials; CLA content in each diet was $0.6 \%$ ) for the high-fat diet.

The compositions of the experimental diets are shown in Table 1. In the CLA and N-CLA groups, 2\% CLA and

\begin{tabular}{|c|c|c|c|c|}
\hline \multirow[t]{2}{*}{ Ingredients } & \multicolumn{4}{|c|}{ g/kg diet } \\
\hline & $\begin{array}{l}\text { Normal } \\
\text { (normal } \\
\text { diet) }\end{array}$ & $\begin{array}{l}\text { Control } \\
\text { (high-fat } \\
\text { diet) }\end{array}$ & $\begin{array}{l}\text { CLA } \\
\text { (HFD + } \\
\text { CLA) }\end{array}$ & $\begin{array}{l}\text { N-CLA } \\
\text { (HFD + } \\
\text { N-CLA) }\end{array}$ \\
\hline Corn starch & 150 & 100 & 100 & 100 \\
\hline Sucrose & 500 & 398.75 & 398.75 & 398.75 \\
\hline Casein & 200 & 200 & 200 & 200 \\
\hline Corn oil & 50 & 50 & 30 & 30 \\
\hline Lard & - & 150 & 150 & 150 \\
\hline Cholesterol & - & I & I & I \\
\hline Sodium chlorate & - & 0.25 & 0.25 & 0.25 \\
\hline Cellulose & 50 & 50 & 50 & 50 \\
\hline Mineral mixture* & 35 & 35 & 35 & 35 \\
\hline Vitamin mixture** & 10 & 10 & 10 & 10 \\
\hline DL-methionine & 3 & 3 & 3 & 3 \\
\hline Choline bitartrate & 2 & 2 & 2 & 2 \\
\hline CLA & - & - & 20 & \\
\hline $\mathrm{N}-\mathrm{CLA}$ & & & & 20 \\
\hline Total & 1000 & 1000 & 1000 & 1000 \\
\hline
\end{tabular}

Table I Composition of experimental diets

Notes: *Mineral mixture (g/kg, AIN-76 mineral mixture, ICN Biomedicals Inc, Irvine, CA, USA): calcium lactate 620.0 , sodium chloride 74.0 , potassium phosphate dibasic 220.0 , potassium sulfate 52.0 , magnesium oxide 23.0 , manganese carbonate 3.3 , ferric citrate 6.0 , zinc carbonate 1.0 , cupric carbonate 0.2 , potassium iodate 0.01 , sodium selenite $0.0 \mathrm{l}$, chromium potassium sulfate 0.5 , finely powdered to make $1000 \mathrm{~g}$. **Vitamin mixture (mg/kg, AIN-76 vitamin mixture, ICN Biomedicals Inc): thiamine $\mathrm{HCl} 600$, riboflavin \pm 600 , pyridoxine $\mathrm{HCl} 700$, nicotinic acid 3000 , D-calcium pantothenate 1600 , folic acid 200, D-biotin 20, vitamin BI2 2.5, vitamin A 400,000 IU, vitamin D3 I00,000 IU, vitamin E $7500 \mathrm{IU}$, vitamin K 75, finely powdered to make $1000 \mathrm{~g}$. Abbreviations: CLA, conjugated linoleic acid; HFD, high-fat diet; N-CLA, nanoemulsified water-soluble conjugated linoleic acid.

N-CLA were added ( $0.6 \%$ CLA content), respectively, instead of corn oil. The care and treatment of animals conformed to the guidelines of Yeungnam University (Gyeongsan, Korea) for the ethical treatment of laboratory animals.

\section{Body weight and feed intake}

Body weight and the amount of food consumed were measured simultaneously at 2-day intervals during the

Table 2 Comparison of body weight gain, food intake, and food efficiency ratio in rats fed the experimental diets for 5 weeks

\begin{tabular}{lcccc}
\hline Item & Normal & Control & CLA & N-CLA \\
\hline $\begin{array}{llll}\text { Food intake and body } \\
\text { Food }\end{array} 28.46 \pm 1.23$ & $27.50 \pm 0.86$ & $28.18 \pm 0.21$ & $28.49 \pm 0.71$ \\
$\begin{array}{l}\text { intake } \\
\text { Body }\end{array}$ & $2.40 \pm 0.58^{\mathrm{a}}$ & $2.89 \pm 0.55^{\mathrm{a}}$ & $2.89 \pm 0.55^{\mathrm{a}}$ & $1.37 \pm 0.3 \mathrm{I}^{\mathrm{b}}$ \\
$\begin{array}{l}\text { weight } \\
\text { gain }\end{array}$ & & & \\
FER $^{*}$ & $0.08 \pm 0.02^{\mathrm{a}}$ & $0.10 \pm 0.02^{\mathrm{a}}$ & $0.11 \pm 0.02^{\mathrm{a}}$ & $0.05 \pm 0.0 \mathrm{I}^{\mathrm{b}}$ \\
\hline
\end{tabular}

Notes: Data are presented as the mean \pm standard deviation $(n=5)$; $F$ FER, food efficiency ratio = body weight gain/food intake; ${ }^{a, b}$ means with different superscripts indicate significant differences $(P<0.05)$. Normal, rats fed a normal diet; control, rats fed a high-fat diet; CLA, rats fed a high-fat diet + $2 \%$ CLA; rats fed a high-fat diet $+2 \%$ N-CLA.

Abbreviations: CLA, conjugated linoleic acid; FER, food efficiency ratio; N-CLA, nanoemulsified water-soluble conjugated linoleic acid. 
Table 3 Size of CLA and N-CLA micelles

\begin{tabular}{lll}
\hline Characteristics & CLA & N-CLA \\
\hline Size $(\mathrm{nm})$ & $17240.60 \pm 3533.27$ & $220.80 \pm 6.98^{*}$ \\
\hline
\end{tabular}

Notes: Data are presented as the mean \pm standard deviation $(n=3)$. *Significant difference $(P<0.001)$.

Abbreviations: CLA, conjugated linoleic acid; N-CLA, nanoemulsified watersoluble conjugated linoleic acid.

experimental period. The feed efficiency ratio was calculated by dividing the amount of body weight gained during the experimental period by the amount of diet consumed during the same period.

\section{Collection of serum and tissue samples}

Blood was collected from the inferior vena cava of rats fasted for 12 hours prior to sacrifice under ether anesthesia on day 35 . Blood was centrifuged at $3000 \times \mathrm{g}$ for 15 minutes at $4^{\circ} \mathrm{C}$ to obtain serum. Internal organs and tissues (liver, epididymal white adipose tissue, and perirenal white adipose tissue) were dissected and excised after washing out the blood with ice-cold $0.15 \mathrm{M} \mathrm{KCl}$ buffer solution, followed by washing with phosphate-buffered saline several times. The organs were then weighed after removing the surface moisture. The isolated liver was frozen rapidly in liquid

\section{A}

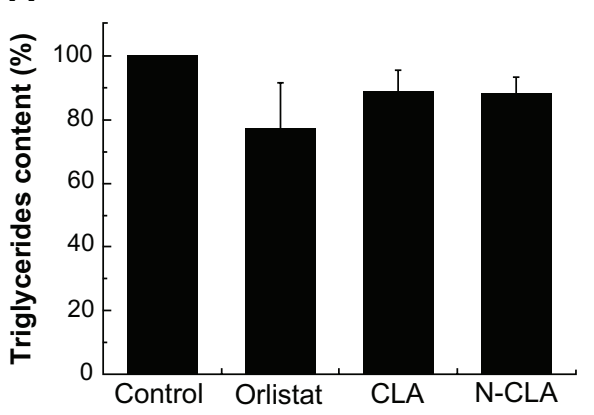

C

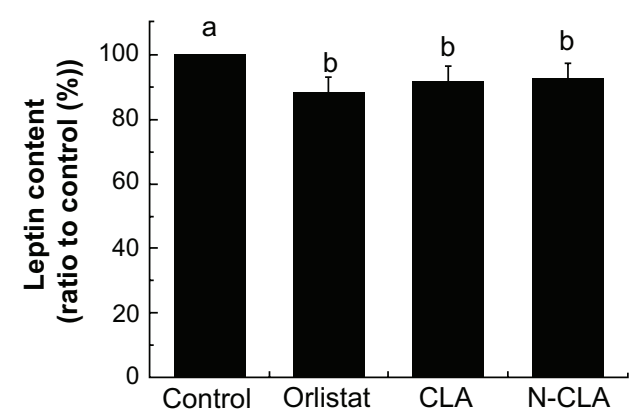

nitrogen and stored at $-70^{\circ} \mathrm{C}$ until the enzyme activity and lipid quantification analyses.

\section{Analyses of serum and liver biochemistry}

Quantification of total serum cholesterol and neutral lipids was performed using a kit from Asan Pharmaceutical Co (Seoul, Korea). High-density lipoprotein (HDL) cholesterol content was measured using a kit reagent (Asan Pharmaceutical Co). Low-density lipoprotein (LDL) cholesterol content was calculated as:

$$
\begin{aligned}
\text { LDL cholesterol }= & \text { Total cholesterol }- \text { HDL cholesterol } \\
& -(\text { neutral lipid } / 5) .
\end{aligned}
$$

The lipid content in liver tissue was measured according to the Folch method. ${ }^{15}$ Briefly, a solution of chloroform and methanol (ratio 2:1) was added to $1 \mathrm{~g}$ of liver tissue, after which the mixture was homogenized. The solution was stored at $4^{\circ} \mathrm{C}$ for 3 days with shaking every 12 hours. After 3 days, the chloroform and methanol solution layer, which was separated from the water layer, was isolated using a pipette, and dry lipids were obtained by evaporating the chloroform and methanol solution in an $80^{\circ} \mathrm{C}$ water bath. The dry lipids were then dissolved in anhydrous ethanol,
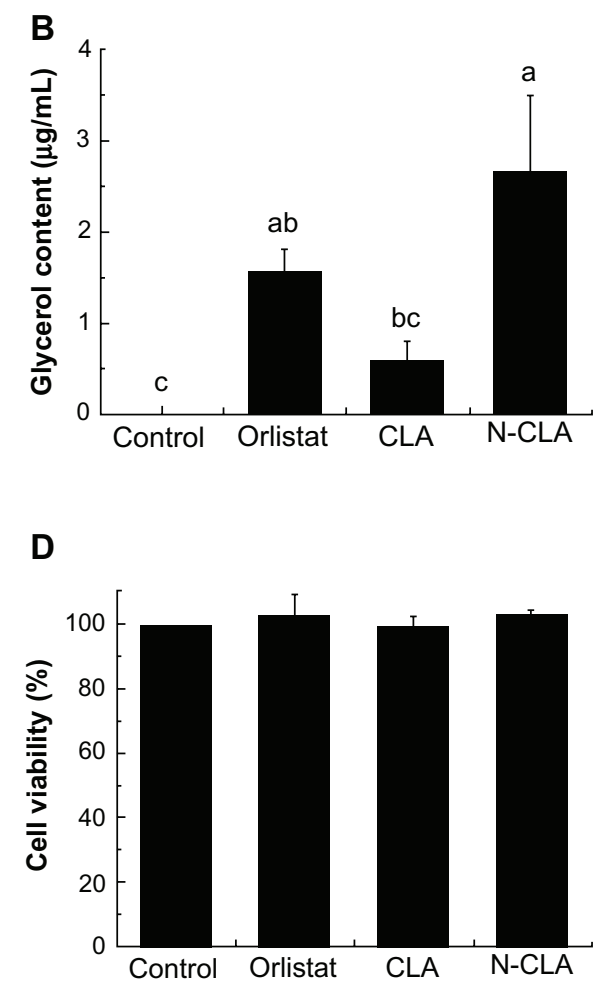

Figure I Effect of N-CLA on viability of preadipocytes (A), triglyceride accumulation (B), free glycerol content (C), and leptin secretion (D) in differentiated adipocytes. Notes: Data are presented as the mean \pm standard deviation. ${ }^{a-c}$ Not sharing the same letter indicates a significant difference between groups at $P<0.05$. Control, treated with vehicle (dimethylsulfoxide) only; orlistat, treated with $10 \mu \mathrm{g} / \mathrm{mL}$ as a positive control; CLA, treated with $10 \mu \mathrm{g} / \mathrm{mL}$ of CLA; N-CLA, treated with $10 \mu \mathrm{g} / \mathrm{mL}$ of N-CLA. Abbreviations: CLA, conjugated linoleic acid; N-CLA, nanoemulsified water-soluble conjugated linoleic acid. 
after which the content of neutral lipids, total cholesterol, and HDL cholesterol were measured using a kit reagent (Asan Pharmaceutical Co).

\section{Statistical analysis}

Data from the individual experiments are expressed as the mean \pm standard deviation. All statistical analyses were performed using Statistical Package for the Social Sciences version 18.0 for Windows software (SPSS, Chicago, IL, USA). One-way analysis of variance and the $t$-test were used for multiple comparisons. Treatment effects were analyzed using Duncan's multiple range tests or the Student's $t$-test. Differences were considered to be statistically significant at $P<0.05$.

\section{Results and discussion}

\section{Size distribution of N-CLA in water phase}

N-CLA micelles were in a fine emulsion state with a size of $220.8 \mathrm{~nm}$, which was almost 80 times smaller than that of CLA micelles (17,240.6 nm, Table 3 and Figure 5). Jani et al observed that the absorption of nanoparticles improved when various sizes of $\mathrm{I}^{125}$-labelled polystyrene latex microspheres $(50 \mathrm{~nm}-3 \mu \mathrm{m})$ were used in rats over 10 days. The results further indicated that nanoparticles with a size up to $300 \mathrm{~nm}$ are able to reach the bloodstream due to increased absorption through the intestine. ${ }^{16}$ Solubilization, absorption, and metabolism are considered to be three important steps that improve the bioavailability of natural bioactive compounds. ${ }^{17}$ Bioactive compounds having low solubility in water, such as curcumin, are usually found in feces following oral administration. ${ }^{18}$ On the other hand, Yu and Huang revealed that nanoemulsified curcumin has a higher permeation ratio than unformulated curcumin due to digestion-diffusion. ${ }^{17}$

\section{Lipolytic effect of N-CLA on mature 3T3-LI adipocytes}

Two major regulation strategies can be used to reduce the adipose tissue mass. The first strategy involves reduction of adipose volume by activation of lipolysis, and the second involves preventing preadipocytes from becoming mature adipocytes. ${ }^{19}$

The lipolytic effect of N-CLA was analyzed in completely differentiated adipocytes. Orlistat, CLA, and N-CLA reduced the level of triglycerides compared with the control, albeit not to a statistically significant extent (Figure 1A). The lipolytic effect of N-CLA in differentiated adipocytes was determined by measuring the amount of glycerol released into the test medium. The glycerol level for each treatment is shown in
Figure 1C. CLA treatment induced lipolysis compared with the control, resulting in a higher glycerol content in the test medium. Orlistat also increased the glycerol content in the test medium by up to $1.57 \mu \mathrm{g} / \mathrm{mL}$. Moreover, the glycerol content after treatment with N-CLA was $2.67 \mu \mathrm{g} / \mathrm{mL}$, which was the highest value (Figure 1B). The inhibitory effect of N-CLA against 3T3-L1 adipocytes was evaluated using an indirect method to determine accumulation of triglycerides in adipocytes during cell differentiation, and no dramatic changes were observed (data not shown).

Orlistat, CLA, and N-CLA all reduced leptin secretion by $11.6 \%, 8.3 \%$, and $7.8 \%$, respectively, compared with the

A

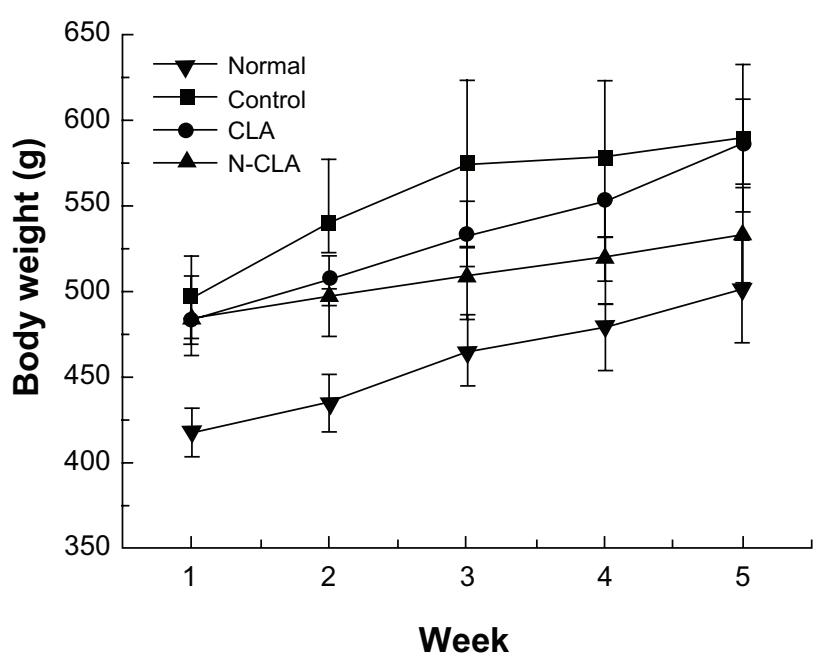

B

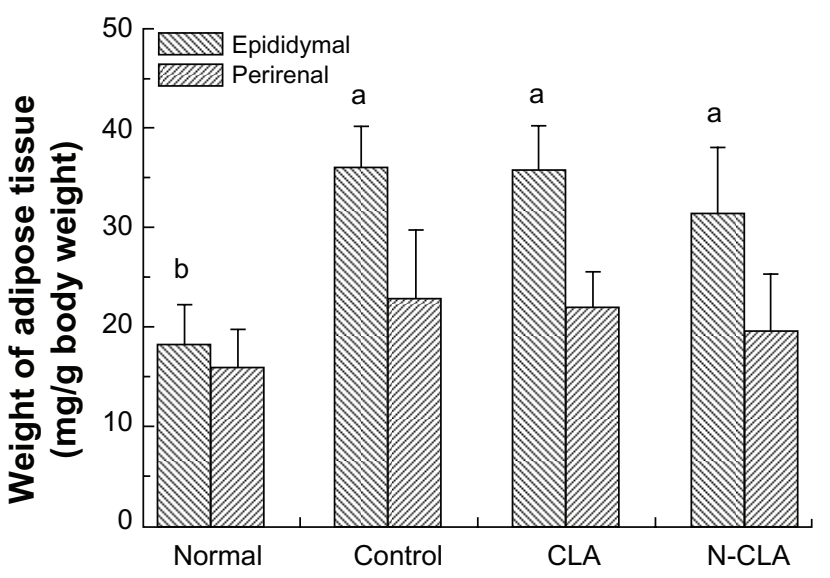

Figure 2 Changes in body weight $(\mathbf{A})$ and adipose tissue weight $(\mathbf{B})$ in rats fed an experimental diet for 5 weeks.

Notes: Data are presented as the mean \pm standard deviation. a,b Not sharing a same letter indicates a significant difference between groups at $P<0.05$. Normal, rats fed a normal diet; control, rats fed a high-fat diet; CLA rats fed on a high-fat diet and $2 \%$ CLA, ( $0.6 \%$ CLA content); N-CLA, rats fed a high-fat diet + $2 \%$ N-CLA ( $0.6 \%$ CLA content). Abbreviations: CLA, conjugated linoleic acid; N-CLA, nanoemulsified watersoluble conjugated linoleic acid. 
control (Figure 1C). In support of this result, Pérez-Matute et al reported that CLA has a direct inhibitory effect on both basal and insulin-stimulated leptin gene expression as well as secretion in primary cultured rat adipocytes. ${ }^{20} \mathrm{Kang}$ and Pariza also observed that the trans-10,cis-12 CLA isomer directly inhibits leptin secretion in 3T3-L1 cells. ${ }^{21}$ In contrast, trans-10,cis-12 CLA has been shown to increase leptin expression in human adipocytes. ${ }^{22}$ Thus, N-CLA had a significant lipolytic effect due to degradation of triglycerides, and it reduced leptin secretion in mature adipocytes to an extent similar to that seen with orlistat.

Orlistat is a well known drug that was designed to treat obesity by diminishing fat accumulation in the body. It acts as a weight management agent by inhibiting gastrointestinal lipase activity and consequently reduces dietary fat absorption. ${ }^{23}$ However, orlistat has gastrointestinal side effects, including fatty and oily stools, fecal urgency, and oily spotting, so requires adherence to a strict dietary regimen of fat-soluble nutrients. ${ }^{24,25}$

Orlistat, CLA, and N-CLA had no cytotoxic effects on the preadipocytes (Figure 1D). Brodie et al reported that 50 or $100 \mu \mathrm{M}$ of CLA has no effect on cell viability. ${ }^{26}$ Further, they suggested that the lipolytic effect of CLA could be attributed to reduction of adipose tissue mass through loss of stored lipids rather than adipocyte numbers.

\section{Effects of N-CLA on body and adipose tissue weights in rats fed a high-fat diet}

Changes in body weight are shown in Figure 2A. Body weight in all groups of rats steadily increased during the experimental period, whereas the rats treated with CLA and N-CLA showed significantly decreased body weight, to levels lower than that in the control group. Further, N-CLA dramatically inhibited body weight gain and maintained a lower feed efficiency ratio during the entire experimental period (Table 2). Previous reports have suggested that CLA has no effect on food intake or food efficiency in animals fed a normal diet, but that it significantly inhibits body weight gain in animals fed a highfat diet. ${ }^{27,28}$ Together, these results show that N-CLA is more efficient than CLA in reducing body weight.

Changes in epididymal and perirenal white adipose tissue weights are shown in Figure 2B. Epididymal and perirenal white adipose tissue weights in the N-CLA treatment group decreased slightly compared with those in the control group. Previous studies have also reported that CLA reduces perirenal adipose tissue weight in mice fed a high-fat diet. ${ }^{29}$
A

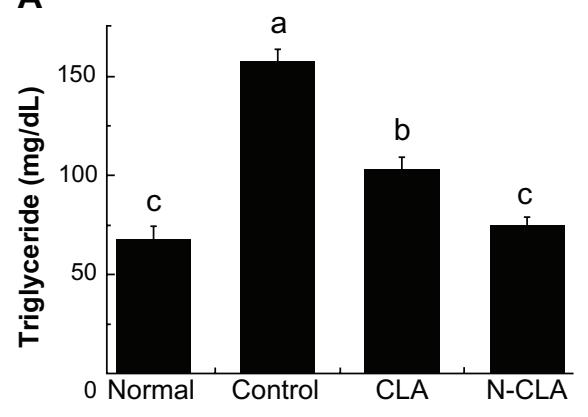

C

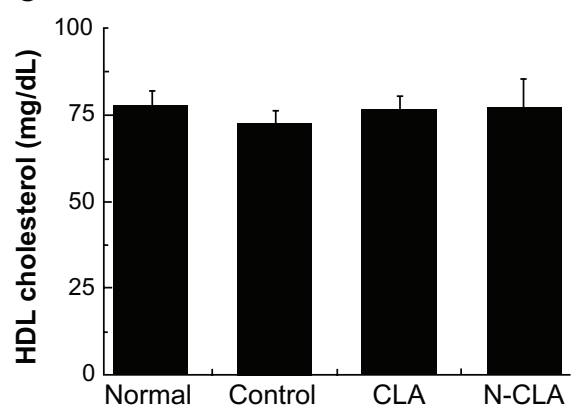

B

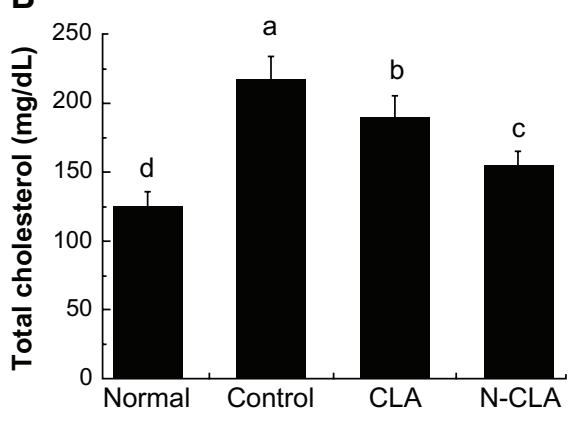

D

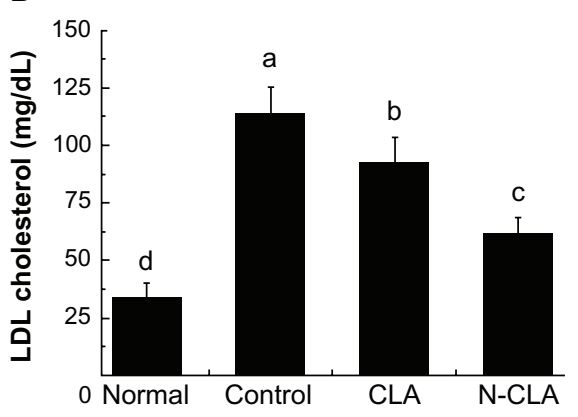

Figure 3 Lipid serum profiles in rats fed a high-fat diet for 5 weeks. Serum concentrations of triglycerides (A), and total (B), HDL (C), and LDL (D) cholesterol. Notes: Data are presented as the mean \pm standard deviation. ${ }^{a-d}$ Not sharing the same letter indicates a significant difference between groups at $P<0.05$. Normal, rats fed a normal diet; control, rats fed a high-fat diet; CLA, rats fed a high-fat diet + $2 \%$ CLA ( $0.6 \%$ CLA content); N-CLA, rats fed a high-fat diet + $2 \%$ N-CLA ( $0.6 \%$ CLA content).

Abbreviations: CLA, conjugated linoleic acid; N-CLA, nanoemulsified water-soluble conjugated linoleic acid; LDL, low-density lipoprotein; HDL, high-density lipoprotein. 
However, in our study, CLA did not have any dramatic effect on adipose tissue weight compared with the control, most likely due to variation in the treatment concentrations.

\section{Effect of N-CLA on cholesterol and triglyceride levels in rats fed a high-fat diet}

As shown in Figure 3, rats fed a high-fat diet had significantly higher serum triglyceride levels compared with rats fed a normal diet. N-CLA significantly decreased triglyceride levels compared with control and CLA-treated rats. Triglyceride levels in rats treated with N-CLA were markedly reduced to $52 \%$ that of the control, and were similar to levels in rats fed a normal diet. Further, N-CLA was also more effective than CLA in reducing both total and LDL cholesterol, decreasing serum levels to $20 \%$ and $46 \%$, respectively. Although no significant difference in serum HDL level was observed between the treatment groups, N-CLA slightly improved HDL levels compared with the control. Moreover, N-CLA treatment significantly decreased serum levels of triglycerides, total cholesterol, and LDL compared with control and CLA (Figure 3). In support of our results, previous reports by Nicolosi et $\mathrm{al}^{130}$ and Munday et $\mathrm{al}^{31}$ have shown that dietary CLA significantly lowers serum total cholesterol, whereas HDL cholesterol remains unaltered. We also observed no significant difference in serum HDL level between the different treatment groups (Figure 3C).

\section{Effect of N-CLA on liver triglyceride and cholesterol levels in rats fed \\ a high-fat diet}

Rats fed a high-fat diet fed showed significantly higher triglyceride and total cholesterol levels in liver tissue compared with rats fed a normal diet (Figure 4). Both CLA and N-CLA significantly reduced triglycerides and total cholesterol levels in liver tissue compared with the control, whereas treatment with N-CLA reduced liver triglyceride and cholesterol levels more effectively compared with CLA (Figure 4B). On the other hand, the literature has shown varying liver triglyceride and cholesterol levels, depending on the animal model used. Some studies have reported that CLA is ineffective in lowering cholesterol in the livers of normal mice, ${ }^{32,33}$ whereas Kim et al reported that CLA in esterified and free forms can effectively reduce triglyceride and cholesterol levels in the livers of obese mice. ${ }^{28}$

The potential mechanism behind the antiobesity effect of CLA has been well documented. CLA supplementation reduces adiposity via regulation of energy metabolism, reduction of energy intake with increased energy expenditure, reduction of lipogenesis or adipogenesis, increased lipolysis, and activation of apoptosis via induction of adipocyte stress, inflammation, and/or insulin resistance. ${ }^{34}$ Based on these data, we propose a mechanism by which N-CLA attenuates body weight with no significant change in fat depots related to energy metabolism. Because N-CLA has a significant impact on the food efficiency ratio, we speculate that N-CLA enhances energy expenditure with no effect on energy intake through suppression of appetite. Further, the remarkable effect of N-CLA is related to its improved bioavailability due to increased absorption into cells and animal organs. However, it is unclear whether or not N-CLA is well absorbed in the body. Thus, to clarify the antiobesity effect of N-CLA,

\section{A}

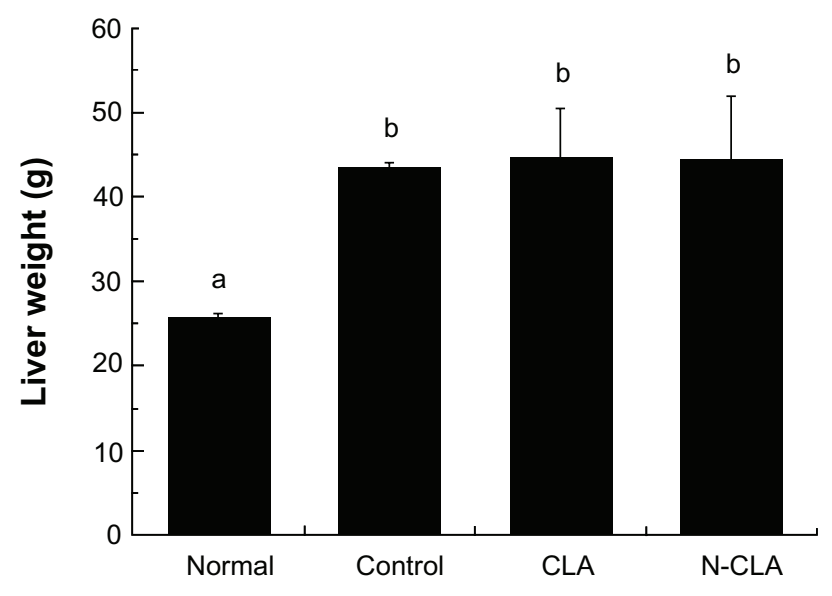

B

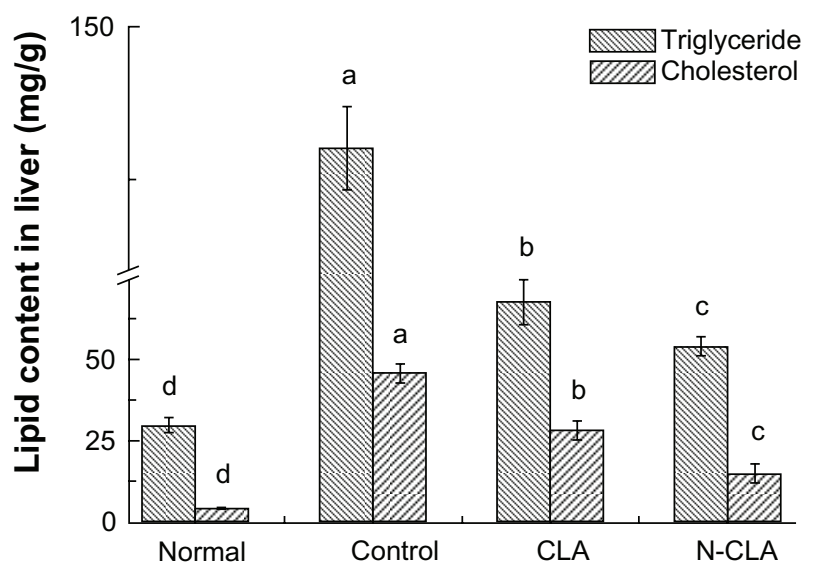

Figure 4 Liver weight $(\mathbf{A})$ and lipid profiles $(\mathbf{B})$ in liver tissue from rats fed a high-fat diet for 5 weeks.

Notes: Triglyceride and cholesterol levels in hepatic tissue are shown as the mean \pm standard deviation. ${ }^{a-d}$ Not sharing the same letter indicates a significant difference between groups at $P<0.05$. Normal, rats fed a normal diet; control, rats fed a highfat diet; CLA, rats fed a high-fat diet $+2 \%$ CLA $(0.6 \%$ CLA content); N-CLA, rats fed a high-fat diet $+2 \% \mathrm{~N}-\mathrm{CLA}(0.6 \%$ CLA content)

Abbreviations: CLA, conjugated linoleic acid; N-CLA, nanoemulsified watersoluble conjugated linoleic acid. 
A

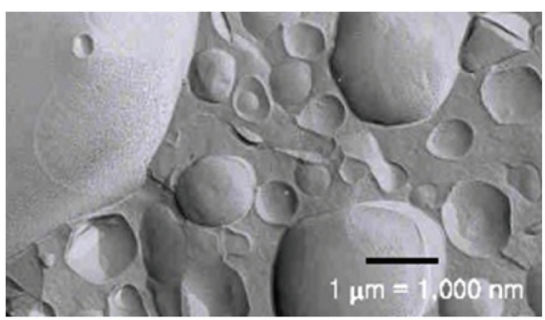

B

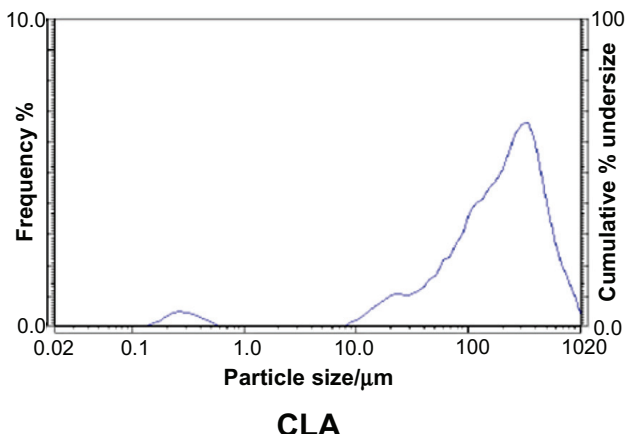

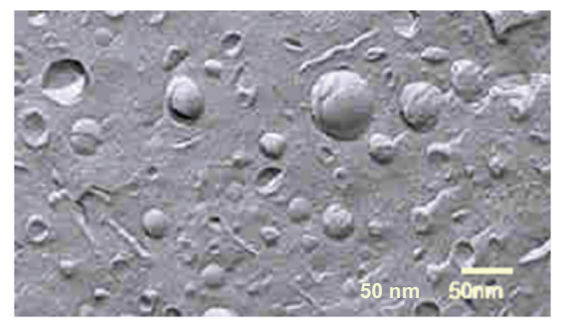

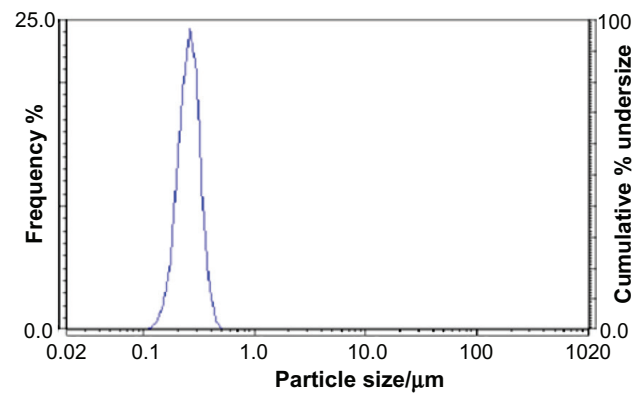

$\mathrm{N}-\mathrm{CLA}$

Figure 5 Size of N-CLA compared with that of CLA. (A) Scanning electron micrographs of CLA and N-CLA. (B) Micelle size distribution of emulsified CLA and N-CLA. Abbreviations: CLA, conjugated linoleic acid; N-CLA, nanoemulsified water-soluble conjugated linoleic acid.

a long-term experiment should be performed using a probe to trace the absorption of N-CLA into cells along with a permeation experiment to establish its circulation in the body from cell monolayers.

\section{Conclusion}

The present work demonstrates that N-CLA is more effective than CLA in reducing fat accumulation in the body, most likely due to improved absorption of fine emulsified CLA. In this study, N-CLA effectively reduced body weight and improved cholesterol and triglyceride levels in the blood and liver compared with CLA. These results indicate that N-CLA can be adapted for enhancing the bioavailability of CLA, which is unstable in water. Thus, N-CLA could potentially be used as an antiobesity agent.

\section{Disclosure}

The authors report no conflicts of interest in this work.

\section{References}

1. Kang JG, Park CY. Anti-obesity drugs: a review about their effects and safety. Diabetes Metab J. 2012;36:13-25.

2. Wahle KW, Heys SD, Rotondo D. Conjugated linoleic acids: are they beneficial or detrimental to health? Prog Lipid Res. 2004;43:553-587.

3. Moloney F, Yeow TP, Mullen A, Nolan JJ, Roche HM. Conjugated linoleic acid supplementation, insulin sensitivity, and lipoprotein metabolism in patients with type 2 diabetes mellitus. Am J Clin Nutr. 2004;80: 887-895.
4. Silveira MB, Carraro R, Monero S, Tébar J. Conjugated linoleic acid (CLA) and obesity. Public Health Nutr. 2007;10:1181-1186.

5. Park Y, Storkson JM, Albright KJ, Liu W, Pariza MW. Evidence that the trans-10,cis-12 isomer of conjugated linoleic acid induces body composition changes in mice. Lipids. 1999;34:235-241.

6. Blankson H, Stakkestad JA, Fagertun H, Thom E, Wadstein J, Gudmundsen O. Conjugated linoleic acid reduces body fat mass in overweight and obese humans. J Nutr. 2000;130: 2943-2948.

7. Delany JP, Blohm F, Truett AA, Scimeca JA, West DB. Conjugated linoleic acid rapidly reduces body fat content in mice without affecting energy intake. Am J Physiol. 1999;276:R1172-R1179.

8. Martinez K, Kennedy A, West T, Milatovic D, Aschner M, McIntosh M. Trans-10cis-12-conjugated linoleic acid instigates inflammation in human adipocytes compared to preadipocytes. $J$ Biol Chem. 2010;285:17701-17712.

9. Tadros TF, Vincent B. Emulsion stability. In: Becher P, editor. Encyclopedia of Emulsion Technology Volume 1. New York, NY: Marcel Deckker; 1983.

10. Shah P, Bhalodia D, Shelat P. Nanoemulsion: a pharmaceutical review. Syst Rev Pharm. 2010;1:24-32. http://www.sysrevpharm.org/text. asp?2010/1/1/24/59509.

11. Bernardi DS, Pereira TA, Maciel NR, et al. Formation and stability of oil-in-water nanoemulsions containing rice bran oil: in vitro and in vivo assessments. J Nanobiotechnology. 2011;9:44.

12. Satory DL, Smith SB. Conjugated linoleic acid inhibits proliferation but stimulates lipid filling of murine 3T3-L1 preadipocytes. J Nutr. 1999; 129:92-97.

13. Fan JP, Kim HS, Han GD. Induction of apoptosis by L-carnitine through regulation of two main pathways in Hepa1c1c7 cells. Amino Acids. 2009;36:365-372.

14. Mimura M, Nabeshima R, Maeda M, Shiomi N. A highly sensitive enzyme-linked immunosorbent assay for quantification of adipocytokines secreted by mouse adipocytes. Biochem Eng J. 2009;43: 58-63.

15. Folch J, Lees M, Sloane-Stanley GH. A simple method for preparation of total pure lipid extracts from brain. Fed Proc. 1954;13:209. 
16. Jani P, Halbert GW, Langridge J, Florence AT. Nanoparticle uptake by the rat gastrointestinal mucosa: quantitation and particle size dependency. J Pharm Pharmacol. 1990;42:821-826.

17. Yu H, Huang Q. Investigation of the absorption mechanism of solubilized curcumin using Caco-2 cell monolayers. J Agric Food Chem. 2011;59: 9120-9126.

18. Sharma RA, Euden SA, Platton SL, et al. Phase I clinical trial of oral curcumin: biomarkers of systemic activity and compliance. Clin Cancer Res. 2004;10:6847-6854.

19. Dagon Y, Avraham Y, Berry EM. AMPK activation regulates apoptosis, adipogenesis, and lipolysis by eIF $2 \alpha$ in adipocytes. Biochem Biophys Res Commun. 2006;340:43-47.

20. Pérez-Matute P, Marti A, Martínez JA, et al. Conjugated linoleic acid inhibits glucose metabolism, leptin and adiponectin secretion in primary cultured rat adipocytes. Mol Cell Endocrinol. 2007;268: 50-58.

21. Kang K, Pariza MW. Trans-10,cis-12-conjugated linoleic acid reduces leptin secretion from 3T3-L1 adipocytes. Biochem Biophys Res Commun. 2001;287:377-382.

22. Brown JM, Boysen MS, Jensen SS, et al. Isomer-specific regulation of metabolism and PPAR $\gamma$ signaling by CLA in human preadipocytes. J Lipid Res. 2003;44:1287-1300.

23. Guerciolini R. Mode of action of orlistat. Int J Obes Relat Metab Disord. 1997;21:S12-S23.

24. Padwal RS, Majumdar SR. Drug treatments for obesity: orlistat, sibutramine, and rimonabant. Lancet. 2007;369:71-77.

25. Jevitt C. Drugs to promote optimum weight. In: King TL, Brucker MC, editors. Pharmacology for Women's Health. Sudbury, UK: Jones and Bartlett Publishers; 2011.
26. Brodie AE, Manning VA, Ferguson KF, Jewell DE, Hu CY. Conjugated linoleic acid inhibits differentiation of pre- and post-confluent 3T3-L1 preadipocytes but inhibits cell proliferation only in preconfluent cells. J Nutr. 1999;129:602-606.

27. Akahoshi A, Koba K, Ohkura-Kaku S, et al. Metabolic effects of dietary conjugated linoleic acid (CLA) isomers in rats. Nutr Res. 2003;23: 1691-1701.

28. Kim JH, Pan JH, Park HG, et al. Functional comparison of esterified and free forms of conjugated linoleic acid in high-fat-diet-induced obese C57BL/6J mice. J Agric Food Chem . 2010;58:11441-11447.

29. West DB, Delany JP, Camet PM, Blohm F, Truett AA, Scimeca J. Effects of conjugated linoleic acid on body fat and energy metabolism in the mouse. Am J Physiol. 1998;275:R667-R672.

30. Nicolosi RJ, Rogers EJ, Kritchevsky D, Scimeca JA, Huth PJ. Dietary conjugated linoleic acid reduces plasma lipoproteins and early aortic atherosclerosis in hypercholesterolemic hamsters. Artery. 1997;22: 266-277.

31. Munday JS, Thompson KG, James KA. Dietary conjugated linoleic acids promote fatty streak formation in the $\mathrm{C} 57 \mathrm{BL} / 6$ mouse atherosclerosis model. Br J Nutr. 1999;81:251-255.

32. Ferramosca A, Savy V, Conte L, et al. Conjugated linoleic acid and hepatic lipogenesis in mouse: role of the mitochondrial citrate carrier. J Lipid Res. 2006;47:1994-2003.

33. Ide T. Interaction of fish oil and conjugated linoleic acid in affecting hepatic activity of lipogenic enzymes and gene expression in liver and adipose tissue. Diabetes. 2005;54:412-423.

34. Kennedy A, Martinez K, Schmidt S, Mandrup S, LaPoint K, McIntosh M. Antiobesity mechanisms of action of conjugated linoleic acid. J Nutr Biochem. 2010;21:171-179.
International Journal of Nanomedicine

\section{Publish your work in this journal}

The International Journal of Nanomedicine is an international, peerreviewed journal focusing on the application of nanotechnology in diagnostics, therapeutics, and drug delivery systems throughout the biomedical field. This journal is indexed on PubMed Central, MedLine, CAS, SciSearch $®$, Current Contents ${ } /$ Clinical Medicine,

\section{Dovepress}

Journal Citation Reports/Science Edition, EMBase, Scopus and the Elsevier Bibliographic databases. The manuscript management system is completely online and includes a very quick and fair peer-review system, which is all easy to use. Visit http://www.dovepress.com/ testimonials.php to read real quotes from published authors. 